\title{
RESEARCH
}

\section{THE EFFECT OF ELDER ABUSE ON PSYCHOLOGICAL RESILIENCE IN INDIVIDUALS 65 YEARS AND OLDER ADMITTED TO THE EMERGENCY DEPARTMENT}

DOI: 10.31086/tigeri.2021.199

$2021 ; 24(1): 50-59$

- Nihal BOSTANCI DAŞTAN ${ }^{1}$

- Handan ÇiFTÇí2

- Fadime KAYA ${ }^{1}$
CORRESPONDANCE

${ }^{1}$ Nihal BOSTANCI DAŞTAN

Kafkas University, Health Sciences Faculty, Nursing Department, Kars, Turkey

\section{Phone: +905052229648}

e-mail: nbdastan@gmail.com

Received: Nov 15, 2020

Accepted: Feb 20, 2021

${ }^{1}$ Kafikas University, Health Sciences Faculty, Nursing Department, Kars, Turkey

2 Kafkas University, Medical Faculty, Emergency Medicine Clinic, Kars, Turkey

\section{Abstract}

Introduction: Elder abuse is an important worldwide problem that increasingly occurs as the population ages and is often kept as a family secret. Emergency department workers play an important role in determining elder abuse and related issues. This study determines the effect of elder abuse on psychological resilience in individuals 65 years and older admitted to the emergency department.

Materials and Method: The study data were obtained from 214 elderly individuals via the Information Form, the Hwalek-Sengstock Elder Abuse Screening Test and the Brief Psychological Resilience Scale. Descriptive statistics, Mann-Whitney-U, Kruskal-Wallis and Spearman Rho Correlation analysis were used to evaluate the data.

Results: The senior's mean age was $74.76 \pm 6.45$ and $51.4 \%$ were men. It was determined that $20.6 \%$ of the seniors had a history of abuse, most of the perpetrators were the spouse $(38.6 \%)$ or siblings $(29.6 \%)$, physical violence was most common (84.4\%) and the violence continued for 1.9\%. The Hwalek-Sengstock Elder Abuse Screening Test mean score was 2.41 1.75 (low), and it was determined that $36.0 \%$ of the seniors experienced abuse. The Brief Psychological Resilience Scale mean score was $18.83 \pm 6.77$, which corresponds to a medium level. A significant negative relationship was evident between the Hwalek-Sengstock Elder Abuse Screening Test and Brief Psychological Resilience Scale scores $(r=-0.238 ; p=.000)$.

Conclusion: Elder abuse is an important problem that requires screening and treatment in emergency departments. As abuse increases, psychological resilience decreases.

Key Words: Elder Abuse; Emergency Service, Hospital; Resilience, Psychological 


\section{INTRODUCTION}

Elderly population growth is an increasing global situation due to advances in health technology and changing fertility rates. Between 2000 and 2050, the proportion of the world's population aged 60 years or over will double from about $11 \%$ to $22 \%$ (1). The proportion of the elderly in the total population was $5.7 \%$ in Turkey in 2005 and is expected to be 17.6 by 2050 in total population (2).

An increase in the elderly population leads to an increase in elder abuse, a problem that has been present throughout history in every culture. Elder abuse is a multidimensional phenomenon that covers a variety of behaviours, events and conditions, and which was accepted as a form of domestic violence in the 1970s (3). The WHO defines elder abuse as 'any behavior that is a single or repeated action in any relationship that threatens or damages the health or well-being of the elderly person'. Elder abuse is classified as physical, sexual, material or psychological/emotional abuse and neglect $(1,3,4)$. Elder abuse and neglect occur in many homes, and the abuser is generally a member of the family $(89.7 \%)(4,5)$. Women, advanced age seniors and those with physical and mental health problems, high stress levels, dementia or cognitive problems, insufficient social support and a history of alcohol or substance abuse constitute high-risk groups for elder abuse $(1,4)$. Elder abuse can lead to physical health problems, such as injuries, permanent injuries and poor health conditions, or psychological problems, such as anxiety, loneliness, loss of honour, trust, hope, depression, reduction in functional capacity and post-traumatic stress disorder. Dong et al. found that abuse is associated with the lowest level of psychological well-being in elder abuse victims. A study conducted in the United States monitored seniors for over 13 years and reported that elder abuse victims were twice as likely to die compared to seniors who did not report any abuse (4-6).

Psychological resilience describes an individual's abilities and resources to successfully cope with ad- verse situations and readjust to their normal lives $(7,8)$. Psychological resilience in the elderly includes being able to cope with boredom, cope with problems and crises, and establish goal-oriented development (9).

In the global health system, $12 \%-24 \%$ of the cases coming to the emergency department are elderly individuals (10). Elder abuse is an increasingly prominent issue for emergency department personnel, as emergency services can be the first point of contact for an elderly person. The first interactions and interventions of emergency service personnel with elder abuse victims can positively affect healthcare outcomes (11). Most of the morbidity and mortality associated with elder abuse stems from a delay in recognition and response (6). Considering that elder abuse increases with ageing and will be an important problem in the near future, it is essential to conduct studies on and find solutions to this issue. However, the number of studies on elder abuse presenting in the emergency department is limited. Based on a lack of national (11) and international $(1,6)$ studies involving elder abuse in emergency services, this study aims to determine the effect of elder abuse on psychological resilience in individuals 65 years and older visiting the emergency department.

\section{METHODS}

\section{Type and Date of Study}

The study was conducted as a cross-sectional analytical study between April 2018 and March 2019.

\section{Study Questions}

- What is the abuse rate of seniors aged 65 years and older visiting the emergency department?

- What factors affect the abuse of seniors aged 65 years and older visiting the emergency department? 
- What effect does elder abuse have on the psychological resilience of individuals aged 65 years and older visiting the emergency department?

\section{Study Population and Sample \\ Population}

The study population comprised all patients aged 65 years and over who visited the emergency department.

\section{Sample}

For sample calculation, it was determined that 5,255 patients aged 65 and over visited the emergency department between March 2018 and March 2019. The sample size was calculated based on the 11\% data obtained the frequency of elder abuse. The formula $n=N t^{2} p q / d^{2}(N-1)+t^{2} p q$ was used for the calculation (12). Using sampling error of 0.05 in the calculation, we obtained a minimum sample number of 147. The patients to be sampled were selected using simple random sampling. A total of 233 individuals over the age of 65 years were interviewed, and the sample comprised 214 seniors (91.8\%).

\section{Data Collection Tools}

Study data were collected using the general information form, the Hwalek-Sengstock Elder Abuse Screening Test (H-S/EAST) and the Brief Psychological Resilience Scale (BPRS).

General information form. The researchers created a questionnaire form comprising 16 questions to obtain demographic information, such as age, gender, marital status, place of growing up, economic status, social security and history of abuse of the participants $(1,3,5,6)$.

\section{Hwalek-Sengstock Elder Abuse Screening Test(H-S/EAST). The H-S/EAST is a two-point Likert-type scale consisting of 14 "yes" and "no" questions divided into three subdimensions: char- acteristics of the vulnerable elderly (3 items), vio- lation of personal rights and direct abuse (5 items)}

and potential abuse ( 6 items). A score of 3 and over shows the presence of abuse, and a higher score indicates a higher potential risk of elder abuse. Ozmete carried out the Turkish liability and reliability study in 2016 and obtained a reliability coefficient of 0.81 (13). The current study also obtained a reliability coefficient of 0.81 .

Brief Psychological Resilience Scale (BPRS). This scale was developed by Smith et al. in 2008 to measure individuals' self-recovery potential and psychological resilience. Dogan adapted the scale to create the Turkish version in 2013. This self-report measurement tool uses a five-point Likert-type scale ranging from 1 (not suitable at all) to 5 (completely suitable). Items 2, 4, and 6 are coded in reverse, but they must first be reversed in the scoring key. High scores indicate high psychological resilience and low scores indicate low psychological resilience (7). A score of 6-11 indicates low psychological resilience, 12-22 medium psychological resilience and 23-30 high psychological resilience (14). Dogan obtained a reliability coefficient of 0.83 (7), compared to 0.86 obtained in the current study.

\section{Ethical Issues}

Approval was obtained from the Ethics Committee on 14 March 2018 (No. 80576354-050-99/45). Additional approval was obtained from the chief physician of the hospital where the study was conducted on 29 March 2018 (No. 66093324-00.99-E.9860) and from the developers of the measurement tools used. Informed consent was obtained from the patients included in the study.

\section{Data Evaluation}

The data obtained in the study were evaluated using SPSS version 20.0. The Shapiro-Wilk normal distribution test was performed after data entry for statistical analysis. According to the test results, the data were not normally distributed. Descriptive statistical methods (mean, number and percentage), including the Mann-Whitney $U$ to compare the means of two groups between the sociodemographic characteristics and scales, the Kruskal-Wal- 
lis test to compare the differences between three and more independent means, and Spearman's Rho Correlation to evaluate the relationships between the $\mathrm{H}-\mathrm{S} / \mathrm{EAST}$ and the BPRS, were used in the statistical analyses. A p-value $<.05$ was considered statistically significant.

\section{RESULTS}

The sociodemographic characteristics of the participants revealed that their mean age was $74.76 \pm 6.45$, $51.4 \%$ were men, $98.5 \%$ were born in the Eastern Anatolian Region of Turkey, $99.0 \%$ grew up there, $63.1 \%$ were married, $50.9 \%$ were illiterate, $52.3 \%$ lived with extended family, $86.0 \%$ had social security, $65.4 \%$ had a medium level economic status and $50.9 \%$ were the only individual in the family that was 65 years or older.

An examination of the participants' abuse history showed that $20.6 \%$ had a history of abuse and that $1.9 \%$ were still being subjected to it. Most of the seniors who experienced abuse $(n=44,20.6 \%)$ stated that the abuser was the spouse $(n=17,38.6 \%)$ or a sibling ( $n=13,29.5 \%)$. Elder abuse took place in the form of physical abuse ( $n=38,86.3 \%$ ), emotional abuse $(n=18,40.9 \%)$ and economic abuse $(n=4$, 9.1\%). The seniors' response to the abuse was not saying anything ( $n=33,75.0 \%)$, going to the police $(n=4,9.1 \%)$, having the abuser apologise and making up ( $n=2,4.5 \%)$, severing relationships with the abuser ( $n=2,4.5 \%)$, leaving home $(n=1,2.3 \%)$ and striking back ( $n=1,2.3 \%)$.

The scale score distributions (Table 1) showed that the H-S/EAST mean score was $2.41 \pm 1.75$ and that the elder abuse level was low. The BPRS mean score was $18.83 \pm 6.77$, indicating a medium level of psychological resilience.

Of the participants, $36.0 \%$ obtained a score of 3 and above on the H-S/EAST, indicating that they had experienced abuse (Figure 1).

A comparison of the H-S/EAST scores according to the participants' sociodemographic characteristics (Table 2) showed that age, gender, marital status, educational level, social security and monthly income level did not create a statistically significant difference in abuse scores ( $p>$.05). However, those living within the nuclear family had vulnerable el-

Figure 1. Elder abuse classification $(n=214)$.

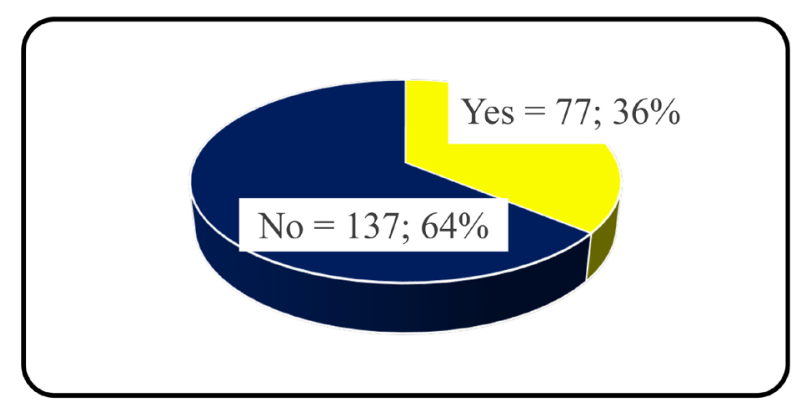

Table 1. Scale Score Distributions

\begin{tabular}{|c|c|c|c|c|}
\hline \multicolumn{2}{|c|}{ Scales } & \multirow{2}{*}{$\begin{array}{c}\text { Achievable Scores } \\
\text { Min - Max Score } \\
0-3 \\
\end{array}$} & \multirow{2}{*}{$\begin{array}{c}\text { In This Study } \\
\text { Min - Max } \\
\text { Score }\end{array}$} & \multirow{2}{*}{$\begin{array}{c}\mathbf{X} \pm \mathrm{SD} \\
1.28 \pm 0.71\end{array}$} \\
\hline \multirow{4}{*}{$\begin{array}{l}\frac{n}{4} \\
\stackrel{\omega}{\omega} \\
\text { I }\end{array}$} & Characteristics of the Vulnerable Elderly & & & \\
\hline & Violation of Personal Rights and Direct Abuse & $0-5$ & $0-4$ & $0.54 \pm 0.85$ \\
\hline & Potential Abuse Situation & $0-6$ & $5-20$ & $0.57 \pm 0.90$ \\
\hline & Total Score & $0-14$ & $0-10$ & $2.41 \pm 1.75$ \\
\hline \multicolumn{2}{|c|}{ BPRS } & $6-30$ & $6-30$ & $18.74 \pm 6.67$ \\
\hline
\end{tabular}


Table 2. Median H-S/EAST Scores According to the Participants' Sociodemographic Characteristics $(n=214)$

\begin{tabular}{|c|c|c|c|c|c|c|c|c|}
\hline \multirow[b]{3}{*}{$\begin{array}{l}\text { Individual } \\
\text { Characteristics }\end{array}$} & \multicolumn{8}{|c|}{ Hwalek-Sengstock Elder Abuse Screening Test (H-S/EAST) } \\
\hline & \multicolumn{2}{|c|}{$\begin{array}{l}\text { Characteristics of the } \\
\text { Vulnerable Elderly }\end{array}$} & \multicolumn{2}{|c|}{\begin{tabular}{|c|} 
Violation of Personal Rights \\
and Direct Abuse
\end{tabular}} & \multicolumn{2}{|c|}{ Potential Abuse Situation } & \multicolumn{2}{|c|}{ TOTAL } \\
\hline & $\begin{array}{l}\text { Mean } \\
\text { Ranks }\end{array}$ & $U ; x^{2} ; p$ & Mean Ranks & $U ; x^{2} ; p$ & Mean Ranks & $U ; x^{2} ; p$ & $\begin{array}{l}\text { Mean } \\
\text { Ranks }\end{array}$ & $\underset{P}{U_{i} x^{2}}$ \\
\hline$A_{g e^{a}}$ & \multicolumn{2}{|c|}{-0.085} & \multicolumn{2}{|c|}{0.090} & \multicolumn{2}{|c|}{0.125} & \multicolumn{2}{|c|}{0.048} \\
\hline \multicolumn{9}{|l|}{ Gender } \\
\hline - Female & 106.53 & \multirow{2}{*}{$\begin{aligned} U & =-0.246 \\
p & =.805\end{aligned}$} & 111.76 & \multirow{2}{*}{$\begin{array}{c}U=-1.132 \\
p=.258\end{array}$} & 114.42 & \multirow{2}{*}{$\begin{array}{c}U=-1.842 \\
p=.066\end{array}$} & 113.86 & \multirow{2}{*}{$\begin{array}{c}U=-1.508 \\
P=.131\end{array}$} \\
\hline - Male & 108.42 & & 103.47 & & 100.96 & & 101.49 & \\
\hline \multicolumn{9}{|l|}{ Marital Status } \\
\hline - Married & 106.96 & \multirow{2}{*}{$\begin{array}{c}U=-0.184 \\
p=.854\end{array}$} & 104.61 & \multirow{2}{*}{$\begin{array}{c}U=-1.030 \\
p=.303\end{array}$} & 103.51 & \multirow{2}{*}{$\begin{aligned} U & =-1.428 \\
p & =.153\end{aligned}$} & 103.74 & \multirow{2}{*}{$\begin{array}{c}U=-1.198 \\
p=.231\end{array}$} \\
\hline - Widow & 108.42 & & 112.43 & & 114.32 & & 113.92 & \\
\hline \multicolumn{9}{|l|}{ Educational Level } \\
\hline - Illiterate & 105.13 & \multirow{5}{*}{$\begin{aligned} x^{2} & =6.684 \\
p & =.154\end{aligned}$} & 110.11 & \multirow{5}{*}{$\begin{aligned} x^{2} & =1.341 \\
p & =.854\end{aligned}$} & 108.17 & \multirow{5}{*}{$\begin{aligned} x^{2} & =4.156 \\
p & =.385\end{aligned}$} & 109.08 & \multirow{5}{*}{$\begin{aligned} x^{2} & =2.594 \\
p & =.628\end{aligned}$} \\
\hline - Literate & 92.24 & & 108.06 & & 106.94 & & 96.81 & \\
\hline - Primary School & 116.10 & & 104.57 & & 103.00 & & 107.96 & \\
\hline - High School & 137.38 & & 89.88 & & 117.00 & & 117.81 & \\
\hline - College/University & 126.00 & & 114.25 & & 177.75 & & 153.25 & \\
\hline \multicolumn{9}{|l|}{ Family type } \\
\hline - Nuclear & 119.35 & \multirow{3}{*}{$\begin{aligned} x^{2} & =7.863 \\
p & =.020\end{aligned}$} & 98.62 & \multirow{3}{*}{$\begin{array}{c}x^{2}=8.498 \\
p=.014\end{array}$} & 100.71 & \multirow{3}{*}{$\begin{aligned} x^{2} & =4.434 \\
p & =.109\end{aligned}$} & 106.56 & \multirow{3}{*}{$\begin{aligned} x^{2} & =3.139 \\
p & =.208\end{aligned}$} \\
\hline - Extended & 97.42 & & 112.20 & & 111.33 & & 105.83 & \\
\hline - Broken & 107.93 & & 152.86 & & 138.28 & & 146.93 & \\
\hline Social Security & & & & & & & & \\
\hline - Yes & 105.04 & $U=-1.587$ & 107.14 & $U=-0.246$ & 109.58 & $U=-1.409$ & 106.98 & $U=-0.312$ \\
\hline - No & 122.57 & $p=.113$ & 109.73 & $p=.805$ & 94.75 & $p=.159$ & 110.67 & $p=.755$ \\
\hline Monthly income level & & & & & & & & \\
\hline - Bad & 123.00 & & 114.40 & & 118.17 & & 125.33 & \\
\hline - Medium & 105.49 & $\begin{aligned} x^{2} & =4.742 \\
p & =.093\end{aligned}$ & 106.25 & $\begin{aligned} x^{2} & =0.918 \\
p & =.632\end{aligned}$ & 104.59 & $\begin{aligned} x^{2} & =2.108 \\
p & =.349\end{aligned}$ & 103.80 & $\begin{aligned} x^{2} & =4.714 \\
p & =.095\end{aligned}$ \\
\hline - Good & 95.97 & & 103.92 & & 106.25 & & 100.30 & \\
\hline Presence of other fami & embers a & d 65 years a & nd older, with w & hom they are & living? & & & \\
\hline - Yes & 103.75 & $U=-0.961$ & 101.71 & $U=-1.551$ & 98.19 & $U=-2.503$ & 98.48 & $U=-2.160$ \\
\hline - No & 111.11 & $p=.337$ & 113.07 & $p=.121$ & 116.47 & $p=.012$ & 116.19 & $p=.031$ \\
\hline
\end{tabular}

a Spearman correlation test is used here. 
derly characteristics compared to those living within the extended family $(p=.020)$, those living in broken families experienced more violation of personal rights and direct abuse compared to those living in a nuclear family $(p=.014)$, and those living without another family member aged 65 years and older had higher potential abuse $(p=0.012)$ subdimension and total abuse $(p=0.031)$ median scores than those living with another family member of their own age.

A comparison of the seniors' abuse history according to H-S/EAST scores (Table 3) showed that the potential abuse $(p=0.028)$ subdimension and total abuse $(p=0.003)$ scores were higher in those with a history of abuse than in those without. In addition, the characteristics of the vulnerable elderly ( $p=0.034$ ) subdimension, the violation of personal rights and direct abuse $(p=0.028)$ subdimension and the total abuse $(p=0.007)$ median scores were significantly higher in those who were currently subjected to abuse than in those who were not.

The examination of the relationships between the participant's H-S/EAST and BPRS scores (Table 4) showed evidence of a statistically significant negative relationship between abuse and psychological resilience $(r=-0.248 ; p<.01)$.

\section{DISCUSSION}

Today, elder abuse is an important social and public health problem that threatens the health of the elderly. In the current study, $20.6 \%$ of the participating seniors had a history of abuse, $1.9 \%$ were still being subjected to it, and most of them were abused by their spouse (38.6\%) or sibling (29.5\%). The forms of abuse included physical abuse (86.3\%), emotional abuse (40.9\%) and economic abuse (9.1\%), and most of the abuse victims (75.0\%) did not say anything after being subjected to the abuse. According to Chokkanathan, the main perpetrators were spouses $(28.0 \%)$, adult children (23.3\%), mothersin-law/grandchild (11.2\%) or others (12.1\%, mostly relatives/neighbours), and approximately $9 \%$ of the abuse victims did not mention their relationship with the perpetrator (15). Rosen et al. reported that the abuser was most frequently the victim's son (37\%), husband (25\%) or daughter (19\%) (6), and Abdel Rahman and El Gaafary reported that 70\% of the perpetrators were daughters-in-law, 59.1\% were daughters or sons and $28 \%$ were spouses (16). As elder abuse is mostly a domestic violence phenomenon, it is often difficult to identify the abuser without obvious signs of physical injury, especially

Table 3. Median H-S/EAST Scores According to the Participants' Abuse History $(n=214)$

\begin{tabular}{|c|c|c|c|c|c|c|c|c|}
\hline \multirow[b]{3}{*}{ Abuse history } & \multicolumn{8}{|c|}{ Hwalek-Sengstock Elder Abuse Screening Test (H-S/EAST) } \\
\hline & \multicolumn{2}{|c|}{$\begin{array}{c}\text { Characteristics of the Vul- } \\
\text { nerable Elderly }\end{array}$} & \multicolumn{2}{|c|}{$\begin{array}{l}\text { Violation of Personal } \\
\text { Rights and Direct Abuse }\end{array}$} & \multicolumn{2}{|c|}{$\begin{array}{c}\text { Potential Abuse } \\
\text { Situation } \\
\end{array}$} & \multicolumn{2}{|c|}{ TOTAL } \\
\hline & Mean Ranks & $U ; x 2 ; p$ & $\begin{array}{l}\text { Mean } \\
\text { Ranks }\end{array}$ & $\mathrm{U} ; \mathbf{X} 2 ; \mathrm{p}$ & $\begin{array}{l}\text { Mean } \\
\text { Ranks }\end{array}$ & $U ; \mathbf{x} 2 ; \mathrm{p}$ & $\begin{array}{l}\text { Mean } \\
\text { Ranks }\end{array}$ & $\begin{array}{l}U_{i} x^{2} \\
p\end{array}$ \\
\hline \multicolumn{9}{|l|}{ Abuse history } \\
\hline - Yes & 119.32 & \multirow{2}{*}{$\begin{array}{c}U=-1.880 \\
p=.060\end{array}$} & 116.42 & \multirow{2}{*}{$\begin{array}{c}U=-1.559 \\
p=.119\end{array}$} & 120.91 & \multirow{2}{*}{$\begin{array}{l}U=-2.203 \\
\mathbf{p}=\mathbf{. 0 2 8}\end{array}$} & 129.06 & \multirow{2}{*}{$\begin{array}{l}U=-2.993 \\
p=.003\end{array}$} \\
\hline - No & 101.84 & & 102.61 & & 101.42 & & 99.26 & \\
\hline \multicolumn{9}{|c|}{ Is the person still subjected to abuse? } \\
\hline - Yes & 62.75 & \multirow{2}{*}{$\begin{array}{c}U=-2.124 \\
p=.034\end{array}$} & 62.25 & \multirow{2}{*}{$\begin{array}{c}U=-2.199 \\
p=.028\end{array}$} & 58.50 & \multirow{2}{*}{$\begin{array}{c}U=-1.801 \\
p=.072\end{array}$} & 70.13 & \multirow{2}{*}{$\begin{array}{l}U=-2.686 \\
p=.007\end{array}$} \\
\hline - No & 39.33 & & 39.36 & & 39.55 & & 38.94 & \\
\hline
\end{tabular}


Table 4. Relationships between H-S/EAST and BPRS Scores $(n=214)$

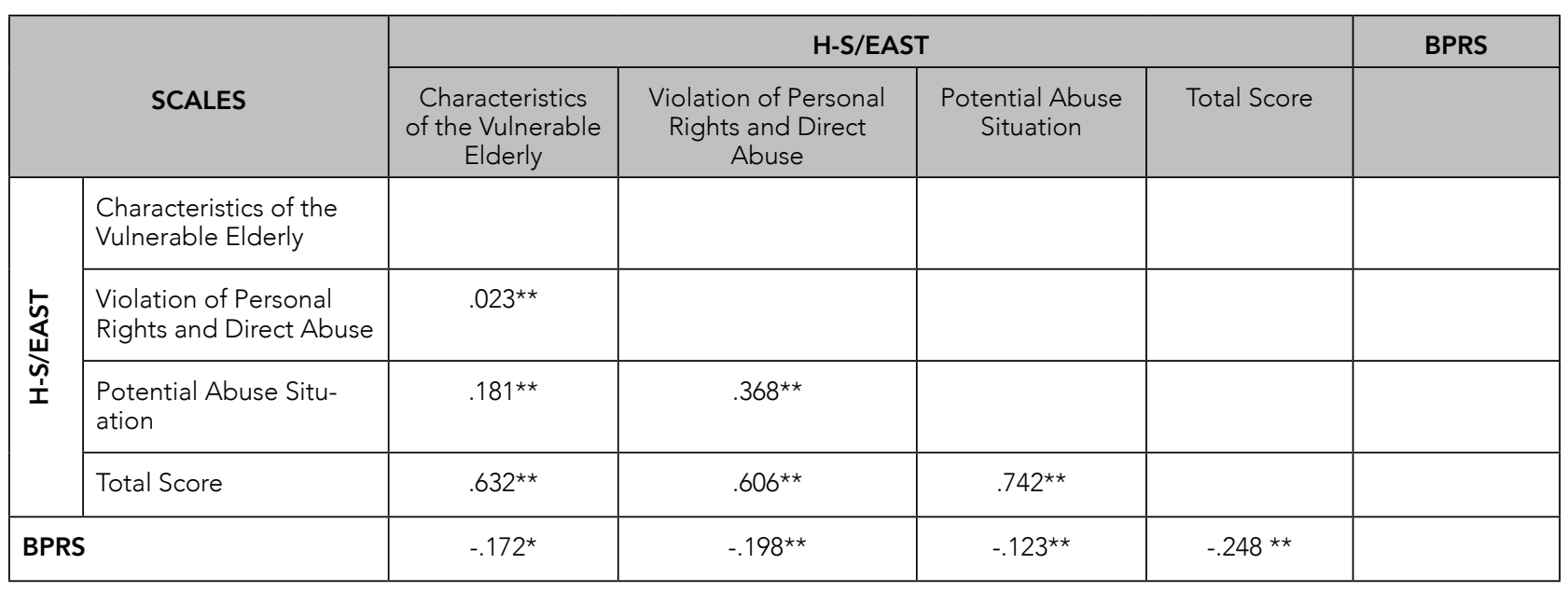

$* p<.05 \quad * * p<.01$

in countries such as Turkey where violence has been made part of society by proverbs such as 'spare the rod and spoil the child', 'beating is a discipline from heaven' and 'don't let it out of this room'. The phenomenon of abuse is often kept secret between the victim and the perpetrator.

According to the distribution of scale scores used in the current study, the abuse level of the elderly was low and their psychological resilience was medium (Table 1). It is thought that the fear of isolation and the fear of being subjected to even more abuse if they say anything is effective in driving the senior's decision to hide the abuse from relatives.

The results showed that $36.0 \%$ of the participating seniors were subjected to abuse (Figure 1). Yon et al. (2019) reported in their meta-analysis research of individuals aged 60 and older that the elderly abuse rate in the last year was $14.1 \%$. The forms of abuse were psychological abuse (11.8\%), neglect (4.1\%), economic abuse (3.8\%), sexual abuse (2.2\%) and physical abuse (1.9\%) (17). Aslan and Erci reported in their study conducted in Malatya/Turkey with individuals aged 65 years and older that $26.8 \%$ of the seniors were subjected to physical abuse, $26.9 \%$ to economic abuse, $12.6 \%$ to sexual abuse and $56.5 \%$ to neglect (18). Chokkanathan obtained an abuse rate of $8.3 \%$ in a study conducted in Singapore with seniors aged 60 years and older (15). In their study on elder abuse conducted in Portugal with individuals aged 60 years and older, Gil et al. reported that the overall prevalence of elder abuse for the previous 12 months was $15 \%$ and that economic and psychological abuse were the most frequent with $6.3 \%$ and sexual abuse was the least frequent with $0.2 \%$ (19). Finally, in their study conducted with individuals aged 60 years and older in West Nigeria, Cadmus and Owoaje found that elder abuse was present among $30 \%$ of the elderly and that the most common forms of abuse were physical abuse (14.6\%), economic abuse (13.1\%), psychological abuse (11.1\%), neglect (1.2\%) and sexual abuse (0.04\%) (20). These differences in the prevalence of elder abuse may arise from differences in the conceptualisation of culture-specific abuse, in the tools used and the study methodology, and from differences in socio-economic levels.

The H-S/EAST score comparison according to the participants' sociodemographic characteristics (Table 2) showed that age, gender, marital status, educational level, social security and monthly in- 
come level did not create a significant difference in abuse scores $(p>$.05). However, the characteristics of the vulnerable elderly were significantly associated with the family type $(p=.020)$ and violation of personal rights $(p=.014)$ subdimensions. In addition, the potential abuse $(p=.012)$ subdimension and total abuse $(p=.031)$ median scores of those not living with another 65 years and older family member were statistically higher than those who were. In the current study, those seniors living in nuclear families and those living in a broken family were more exposed to direct abuse. Participants with no other family member over the age of 65 years were at risk for abuse. The literature indicates that women $(6,16,18,19,20)$, those living alone (15), those living in a broken family/widows/divorcees/ singles $(16,18,21)$, those with a low education level $(18-21)$ and those of advanced age $(16,19,20)$ have an increased rate of exposure to elder abuse. However, Chokkanathan reported that age and gender do not have a significant effect on elder abuse (15).

In the current study, the H-S/EAST score comparison according to the history of abuse (Table 3) revealed that the median scores of abuse were significantly higher in those who had a history of abuse than those who did not and those who were still being exposed to it than those who were not. In the study of Chokkanathan, seniors with a family history of violence experience more abuse (15).

In the current study, as the abuse level increased, the psychological resilience significantly decreased (Table 4) $(r=-0.248 ; p<.01)$. Exposure to abuse and violence, which reduces psychological resilience $(8,15,16,21-24)$, is an external factor (25). Psychological resilience has a protective effect on mental health against the consequences of abuse, which suggests that the higher the resilience level of these individuals, the less anxiety, insufficiency, decreased self-esteem, depression and fatigue they experience.

This study contributes to the existing literature on abuse patterns in elder abuse and the relationship of abuse with psychological status. To our knowledge, this study is the first to investigate and define abuse in elderly patients admitted to the emergency department in our region.

This study has a variety of limitations. Firstly, cross-sectional structure of the study design will not allow us to determine the causative relationships. Secondly the fact that the elderly tend to hide the elderly abuse, have fear that they would be exposed to greater abuse if they told it, usually deny the abuse they are exposed to by their relatives and are ashamed of explaining it, makes it difficult to obtain the data. Thirdly the questionnaire is based on self-report. Although self-report questionnaires are a valuable method in psychological research, relying on such questionnaires alone is a limitation, because there is a potential for subjective prejudice. Prior to applying data collection tools to the elderly who were included in the study, no measurement tool showing whether they were cognitively healthy or not and evaluating their cognitive functions, was applied to them. The results in the study depend on the accuracy of the evaluation of data collection tools by the elderly who were included in the study and their responses to the questionnaire and scale items aimed at determining the abuse prevalence. Fourthly the city where the study was conducted only has two hospitals. The findings of the study were obtained from the elderly coming to the emergency service of only one hospital. Thus the results attained are limited to the data acquired from these people and can not be generalized to all elderly. On the other hand, unclear questions were explained to the elderly with lower cultural and educational level one by one in detail and they were made respond objectively. From this point of view, it is possible to consider this situation a strong aspect of the study in terms of the reliability of results. 


\section{CONCLUSIONS AND RECOMMENDATIONS}

The findings determined that $36.0 \%$ of seniors experienced elder abuse and that psychological resilience significantly decreased as elder abuse levels increased. Emergency department workers are in an ideal position to identify and respond to individuals experiencing elder abuse. Awareness about a situation is the first step in stopping its progression. Training programmes and written protocols should be developed to enable emergency medical professionals to increase their knowledge about vari-

\section{REFERENCES}

1. Phelan A. Elder abuse in the emergency department. Int Emerg Nurs. 2012; 20(4): 214-220. (DOI:10.1016/j. ienj.2012.03.009)

2. Saruipek DB. Demographic shift and elderly care in Turkey. Journal of Social Security 2016; 6(2): 93-112.

3. Fulmer T, Paveza G, Abraham I, Fairchild S. Elder neglect assessment in the emergency department. J Emerg Nurs. 2000; 26(5): 436-443. (PMID: 11015061)

4. Dong XQ. Elder abuse: systematic review and implications for practice. J Am Geriatr Soc. 2015; 63(6): 1214 1238. (PMID: 26096395)

5. Bond M.C, Butler KH. Elder abuse and neglect: definitions, epidemiology, and approaches to emergency department screening. Clin Geriatr Med. 2013; 29(1): 257-273. (PMID: 23177610)

6. Rosen T, Bloemen EM, LoFaso VM, Clark S, Flomenbaum NE, Lachs MS. Emergency department presentations for injuries in older adults independently known to be victims of elder abuse. J Emerg Med. 2016;50(3):518-526. (PMID: 26810019)

7. Dogan T. Adaptation of the Brief Resilience Scale into Turkish: A validity and reliability study. The Journal of Happiness \& Well-Being, 2015;3(1): 93-102. (in Turkish).

8. Serra L, Contador I, Fernándezla Calvo B et al. Resilience and social support as protective factors against abuse of patients with dementia: A study on family caregivers. Int J GeriatrPsychiatry. 2018;33(8):11321138. (PMID: 29797350). ous forms of abuse, related problems and indicators, and effective response methods.

In addition, social welfare interventions at the national level and in line with cultural norms are required to correct this global problem and to increase psychological resilience.

\section{Acknowledgements}

We thank the seniors who participated in this study.

9. Cuevas PEG, Urgel EL, Dela Cruz DC, Mizona KJB. Elder abuse's correlation to health and resilience of older adults. Educational Gerontology 2020; 46(6): 331-338. (DOI:10.1080/03601277.2020.1748813)

10. Samaras N, Chevalley T, Samaras D, Gold G. Older patients in the emergency department: a review. Ann Emerg Med. 2010; 56(3): 261-269. (PMID: 20619500)

11. Mandiracioglu A, Govsa F, Celikli S, Yildirim GO. Emergency health care personnel's knowledge and experience of elder abuse in Izmir. Arch Gerontol Geriatr. 2006; 43(2): 267-276. (PMID: 16332396)

12. Yazıcıoglu Y, Erdogan S. SPSS Applied Scientific Research Methods. Detay Publishing, Turkey 2011, pp.84-90. (in Turkish).

13. Ozmete E. The Hwalek-Sengstock Elder Abuse Screening Test: the adaptation study into Turkish. Anatolian Journal of Psychiatry, 2016; 17(Suppl.1): 4552. (DOI: 10.5455/apd.200727) (in Turkish).

14. Hosoglu R, Kodaz AF, Bingol TY, Vural Batik M. The resilient levels of preservice teachers. OPUS International Journal of Society Studies 2018; 8(14): 217-239. (DOI:10.26466/opus.405751) (in Turkish).

15. Chokkanathan S. Prevalence and correlates of elder mistreatment in Singapore. J Elder Abuse Negl. 2018; 30(4): 271-283. (PMID: 29851567)

16. Abdel Rahman TT, El Gaafary MM. Elder mistreatment in a rural area in Egypt. Geriatrics \& Gerontology International 2011; 12(3): 532-537. (PMID: 22212376)

17. Yon Y, Mikton C, Gassoumis ZD, Wilber KH. The prevalence of self-reported elder abuse among older women in community settings: a systematic review 
and meta-analysis. Trauma, Violence, Abuse. 2019; 20(2): 245-259. (PMID: 29333977)

18. Aslan $H$, Erci B. The incidence and influencing factors of elder abuse and neglect. Journal of Public Health: From Theory to Practice 2019; 28: 525-533. (DOI:10.1007/s10389-019-01071-7)

19. Gil APM, Kislaya I, Santos AJ, Nunes B, Nicolau R, Fernandes AA. Elder abuse in Portugal: findings from the first national prevalence study. J Elder Abuse Negl. 2015; 27(3): 174-195. (PMID: 25122109)

20. Cadmus EO, Owoaje ET. Prevalence and correlates of elder abuse among older women in rural and urban communities in South Western Nigeria. Health Care Women Int. 2012; 33(10): 973-984. (PMID: 22946597)

21. Wu L, Chen $H, H u Y$, et al. Prevalence and associated factors of elder mistreatment in a rural community in People's Republic of China: a cross-sectional study.
PloS One 2012; 7(3): e33857. ( PMID: 22448276)

22. Howell $\mathrm{KH}$. Resilience and psychopathology in children exposed to family violence. Aggress Violent Behav. 2011; 16(6): 562-569. (DOI:10.1016/j. avb.2011.09.001)

23. Anderson KM, Renner LM, Danis FS. Recovery: Resilience and growth in the aftermath of domestic violence. Violence Against Women 2012; 18(11): 12791299. (PMID: 23334815)

24. Anderson KM, Bang EJ. Assessing PTSD and resilience for females who during childhood were exposed to domestic violence. Child \& Family Social Work 2012; 17(1): 55-65. (DOI:10.1111/j.1365-2206.2011.00772.x)

25. Agaibi C. Resilience: A versatile concept from biblical to modern times. The Journal of Happiness and Well-Being 2018; 6(1): 33-48. 